\title{
Prolapse of the Pipeline embolization device in aneurysms: incidence, management, and outcomes
}

\author{
Visish M. Srinivasan, MD, ${ }^{1}$ Andrew P. Carlson, MD, MS-CR, ${ }^{2}$ Maxim Mokin, MD, PhD, ${ }^{3}$ \\ Jacob Cherian, MD, ${ }^{1}$ Stephen R. Chen, MD, ${ }^{4}$ Ajit Puri, MD, ${ }^{5}$ and Peter Kan, MD, MPH ${ }^{1}$
}

\begin{abstract}
Departments of ${ }^{1}$ Neurosurgery and ${ }^{4}$ Radiology, Baylor College of Medicine, Houston, Texas; ' 2 Department of Neurosurgery, University of New Mexico, Albuquerque, New Mexico; ${ }^{3}$ Department of Neurosurgery, University of South Florida, Tampa, Florida; and ${ }^{5}$ Department of Radiology, University of Massachusetts Medical School, Worcester, Massachusetts
\end{abstract}

OBJECTIVE The Pipeline embolization device (PED) is frequently used in the treatment of anterior circulation aneurysms, especially around the carotid siphon, with generally excellent results. However, the PED has its own unique technical challenges, including the occurrence of device foreshortening or migration leading to prolapse into the aneurysm. The authors sought to determine the incidence of this phenomenon, the rescue strategies, and outcomes.

METHODS Four institutional databases of neuroendovascular procedures were reviewed for cases of intracranial aneurysms treated with PEDs. Patient and aneurysm data as well as angiographic imaging were reviewed for all cases involving device prolapse into the aneurysm.

RESULTS A total of 413 intracranial aneurysms were treated with PEDs during the study period, by 5 neurointerventionalists. Large and giant aneurysms $(\geq 2 \mathrm{~cm}$ ) accounted for 32 of these aneurysms. Among these 32 PEDs, prolapse into the aneurysm occurred in 3 patients, with 1 of these PEDs successfully rescued and the other 2 left in situ. No patients suffered any severe complications. The 2 patients in whom the PEDs were left in situ remained on antiplatelet therapy.

CONCLUSIONS The PED may foreshorten or migrate during or after deployment, leading to prolapse into the aneurysm. This phenomenon appears to be associated with large and giant aneurysms, vessel tortuosity, short landing zones, and use of balloon angioplasty. Future study and follow-up is needed to further evaluate this phenomenon, but some of the observations and techniques described in this paper may help to prevent or salvage prolapsed devices.

https://thejns.org/doi/abs/10.3171/2017.3.FOCUS1738

KEY WORDS prolapse; migration; foreshortening; Pipeline embolization device; flow diversion; aneurysm

$\mathrm{T}$ HE Pipeline embolization device (PED; Medtronic) was approved by the US FDA for the treatment of large and giant intracranial aneurysms from the petrous to the superior hypophyseal segment of the internal carotid artery (ICA). It has, in a short time, transformed the treatment paradigm for giant aneurysms that are challenging surgically. However, flow diversion treatment has its own unique challenges and pitfalls, especially in the treatment of very large and giant aneurysms. Foreshortening and migration have been described in intracranial self-expanding stents ${ }^{8,17,18,21,23}$ as well as in several case examples or series with PEDs. ${ }^{3,5-7,14,16,19,25,28}$

A recent series of PEDs for large and giant aneurysms reported a foreshortening/migration in 5 of 47 patients. $^{19}$ This series found tortuous parent artery anatomy to be a contributing factor and salvaged the construct in all these occurrences. However, occasionally the construct cannot be salvaged, despite heroic measures.

In the literature, several terms are used to describe various types of unwanted device movement: "foreshortening," "migration," "deformation," and "prolapse." Among these, foreshortening leading to either device prolapse into the aneurysm or incomplete neck coverage are the most worrisome. A case of incomplete neck coverage without prolapse into the aneurysm can be salvaged with additional devices, because distal access can be regained with rela-

ABBREVIATIONS $\mathrm{BTO}=$ balloon test occlusion; $\mathrm{CTA}=\mathrm{CT}$ angiography; $\mathrm{ICA}=$ internal carotid artery; $\mathrm{PCOA}=$ posterior communicating artery; $\mathrm{PED}=\mathrm{Pipeline}$ embolization device; PTA = percutaneous transluminal angioplasty. 
tive ease. However, true device prolapse into the aneurysm presents a much bigger challenge. In this study, we sought to evaluate the incidence of PED foreshortening leading to prolapse into the aneurysm as well as management strategies and outcomes in these patients.

\section{Methods}

Institutional databases at each participating center (Baylor College of Medicine, University of New Mexico, University of South Florida, and University of Massachusetts) were searched for patients treated with PEDs. We also identified the large $(2.0-2.5 \mathrm{~cm})$ and giant $(\geq 2.5 \mathrm{~cm})$ aneurysms, as in our experience and in the literature, foreshortening and prolapse tend to occur in wide-necked giant aneurysms that require multiple overlapping devices for treatment. Among these, we selected patients who had at least a 6-month clinical and angiographic follow-up duration. Clinical data and all applicable imaging were reviewed. The study was approved by the local IRB of each participating institution.

\section{Procedures}

All procedures were performed under general anesthesia after obtaining appropriate consents. Patients systemically received heparin with an activated clotting time $\geq$ 200 seconds throughout the procedure. PEDs were delivered via a Marksman (Medtronic) or compatible microcatheter in standard fashion with a triaxial system consisting of a 6-Fr guiding catheter or shuttle sheath placed in the common carotid artery, and a 5-Fr Navien distal access catheter (Medtronic) placed proximal to the aneurysm. Satisfactory wall apposition was confirmed with cone-beam CT (DynaCT, Siemens Medical Imaging; or XperCT, Philips Healthcare).

\section{Antiplatelet Regimen}

All patients were treated with a dual antiplatelet regimen $(81 \mathrm{mg}$ or $325 \mathrm{mg}$ of aspirin, and $75 \mathrm{mg}$ of clopidogrel) 7 days prior to elective placement of the PED. Platelet inhibition was checked immediately preceding the procedure with the P2Y12 assay (VerifyNow, Accu- metrics). Clopidogrel nonresponders were changed to an alternative antiplatelet agent. An aspirin response unit value of $\leq 550$ and a clopidogrel response unit of $\leq 220$ were considered an indication of an appropriate level of platelet inhibition for treatment. Patients were maintained on aspirin and clopidogrel for at least 6 months following PED placement, and aspirin indefinitely after. Statistical comparisons (chi-square test) were performed using MedCalc (MedCalc Software bvba).

\section{Results}

The retrospective review of the institutional databases and personal series of 5 neurointerventionalists yielded a total of 413 PED deployments from 2012 to 2016. Among these, there were 32 large and giant aneurysms that were treated. Among these 32, there were 3 cases of PED foreshortening leading to prolapse into the aneurysm, 1 of which was rescued (previously reported, Case 3 by Kan et al.), ${ }^{16}$ and 2 of which were left in situ. The aneurysm characteristics and clinical details are further summarized in Table 1. While the incidence of PED prolapse overall was $0.73 \%$, it was significantly higher $(9.3 \%)$ among large and giant aneurysms $(\mathrm{p}<0.00001)$.

\section{Illustrative Cases \\ Case 1}

An 84-year-old man with a recent myocardial infarction presented with a right lateral rectus palsy. A large right cavernous ICA aneurysm, measuring $20 \times 14 \mathrm{~mm}$ with a 13-mm neck, was identified (Fig. 1A). There was significant proximal vessel tortuosity, and a $4.5 \times 20-\mathrm{mm}$ Pipeline Flex was deployed across the aneurysm neck in the cavernous ICA, with more attention given to having sufficient distal coverage, leaving a shorter proximal segment (Fig. 1B and C). Deployment of a second PED was considered, but there was concern of pushing the proximal end of the PED into the aneurysm while attempting to reaccess the device. Early stasis was observed, and the procedure was considered successful (Fig. 1D). After initial improvement of lateral rectus palsy, the patient developed acute worsening of diplopia at 4 months. Angiographic

TABLE 1. Summary of patient and aneurysm characteristics for 2 PED cases left in situ

\begin{tabular}{lll}
\hline \multicolumn{1}{c}{ Variable } & \multicolumn{1}{c}{ Case 1} & \multicolumn{1}{c}{ Case 2} \\
\hline Age, sex & $84, \mathrm{M}$ & $63, \mathrm{~F}$ \\
\hline Aneurysm location & Cavernous ICA & Cavernous ICA \\
\hline Aneurysm size, neck $(\mathrm{mm})$ & $20 \times 14,13$ & $21 \times 29,7.7$ \\
\hline PED size $(\mathrm{mm})$ & $4.5 \times 20$ & $4.25 \times 30$ \\
\hline Foreshortening end (proximal/distal) & Proximal & Proximal \\
\hline Time course of foreshortening & Delayed & Acute \\
\hline Inflow/outflow vessel size $(\mathrm{mm})$ & $4 / 4.2$ & $4.5 / 5$ \\
\hline Landing zone: proximal/distal $(\mathrm{mm})$ & $<5 / 15$ & $3.1 />5$ \\
\hline Last clinical follow-up & 12 mos & 30 mos \\
\hline Last angiographic imaging & 6 -mo DSA, 12-mo CTA & 12 -mo \& 30-mo CTA \\
\hline Postprocedural antiplatelet protocol & Dual antiplatelet & Dual antiplatelet $\times 12$ mos, then 81 mg of aspirin \\
\hline DSA = digital subtraction angiography. & &
\end{tabular}




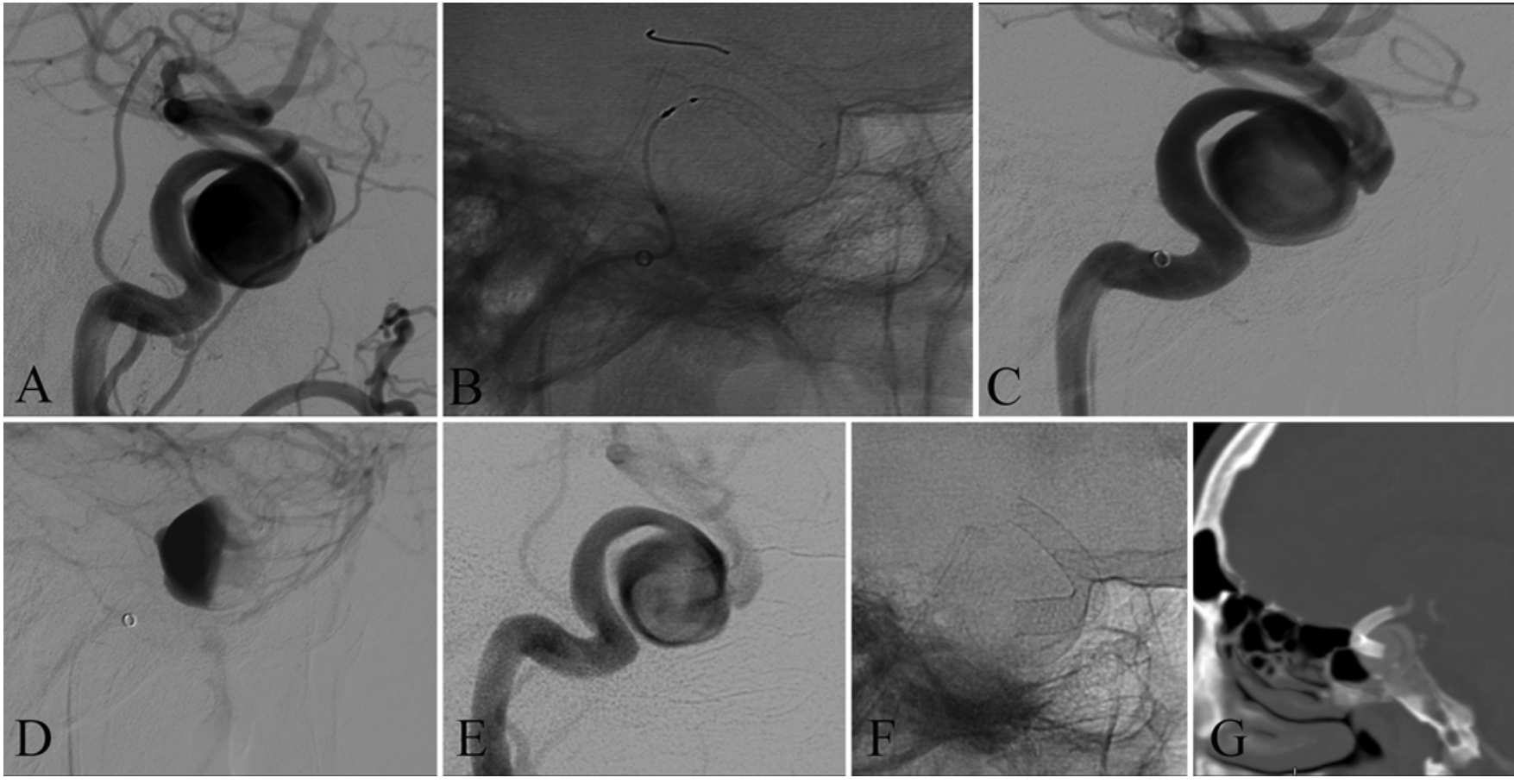

FIG. 1. Case 1, a delayed PED prolapse. A: Angiogram showing a large right cavernous ICA aneurysm, measuring $20 \times 14 \mathrm{~mm}$ with a 13-mm neck. B and C: Fluoroscopic (B) and angiographic (C) images showing the $4 \times 20-\mathrm{mm}$ Pipeline Flex deployed, with sufficient distal coverage but insufficient proximal neck coverage. D: Early stasis is observed in the aneurysm on an angiogram. E and F: At 6-month follow-up, the proximal end of the PED had migrated into the dome of the aneurysm as noted on angiography (E) and fluoroscopy (F). G: The aneurysm remained unchanged on CTA at the 12-month follow-up.

follow-up at 6 months showed that the proximal end of the PED had migrated into the dome of the aneurysm (Fig. 1E and F). As the patient's symptoms were tolerable, further intervention was declined. The patient was maintained on dual antiplatelet therapy thereafter, with no change in the aneurysm on follow-up CT angiography (CTA) at 12 months (Fig. 1G).

\section{Case 2}

A 63-year-old woman harboring a giant right cavernous ICA aneurysm $(21 \times 29 \mathrm{~mm}, 7.7-\mathrm{mm}$ neck), was referred for endovascular treatment (Fig. 2A). She was symptomatic with symptoms of right-hemisphere ischemia, and had failed previous attempts at a balloon test occlusion (BTO) and extracranial-intracranial bypass. The PED $(4.25 \times$ $30 \mathrm{~mm}$ ) took a tortuous path through the aneurysm and left a precariously short proximal landing zone $(3.1 \mathrm{~mm}$; Fig. 2B). The PED was inadvertently bumped by the microcatheter during recapture of the distal wire, and the proximal PED foreshortened and prolapsed into the aneurysm (Fig. 2C). Distal access was also lost at the same time. Attempts at regaining access, both anterograde, and retrograde through the posterior communicating artery ( $\mathrm{PCoA})$, were unsuccessful. A snare was also used in an attempt to pull the distal stent into the aneurysm to allow deployment of a new device, also unsuccessfully (Fig. 2D). The device was left in situ with the proximal PED in the aneurysm, and the patient was maintained on $81 \mathrm{mg}$ of aspirin daily after receiving dual antiplatelet therapy for 1 year. The patient was clinically asymptomatic at the
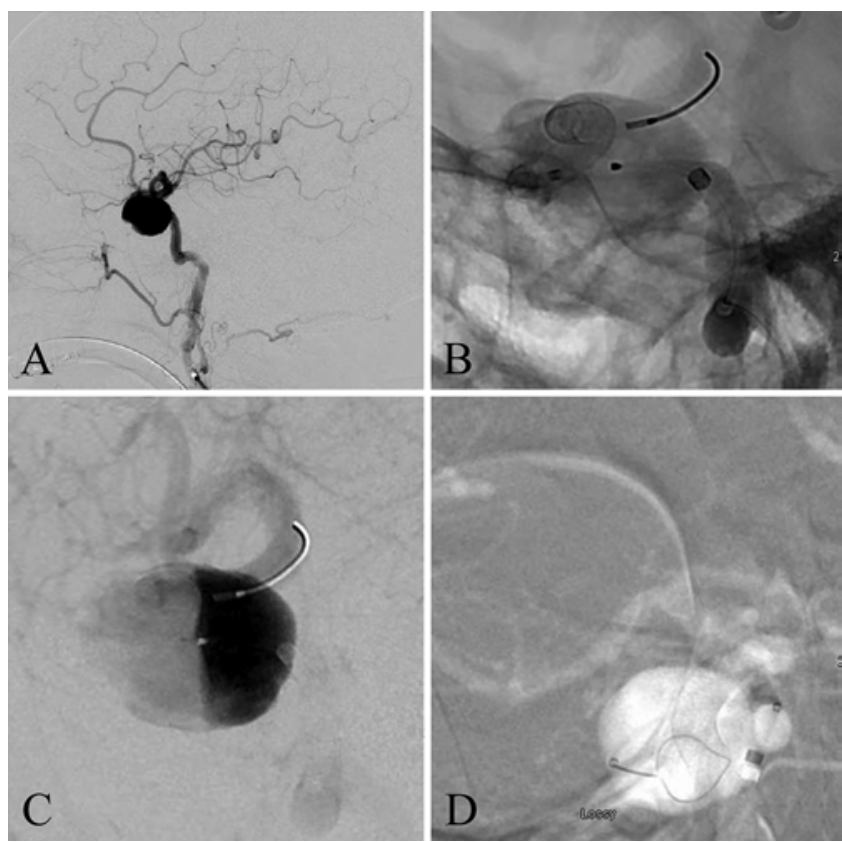

FIG. 2. Case 2, an acute PED prolapse. A: Angiogram showing a $21 \times$ 29-mm right ICA aneurysm, with a 7.7-mm neck. B: A $4.25 \times 30-\mathrm{mm}$ PED was deployed, taking a tortuous path through the aneurysm as noted on fluoroscopy. C: Initially, the device was deployed with rapid stasis within the aneurysm, as observed on this angiogram. D: Roadmap angiographic image showing the proximal end of the device foreshortened into the aneurysm, with failed rescued attempts. 


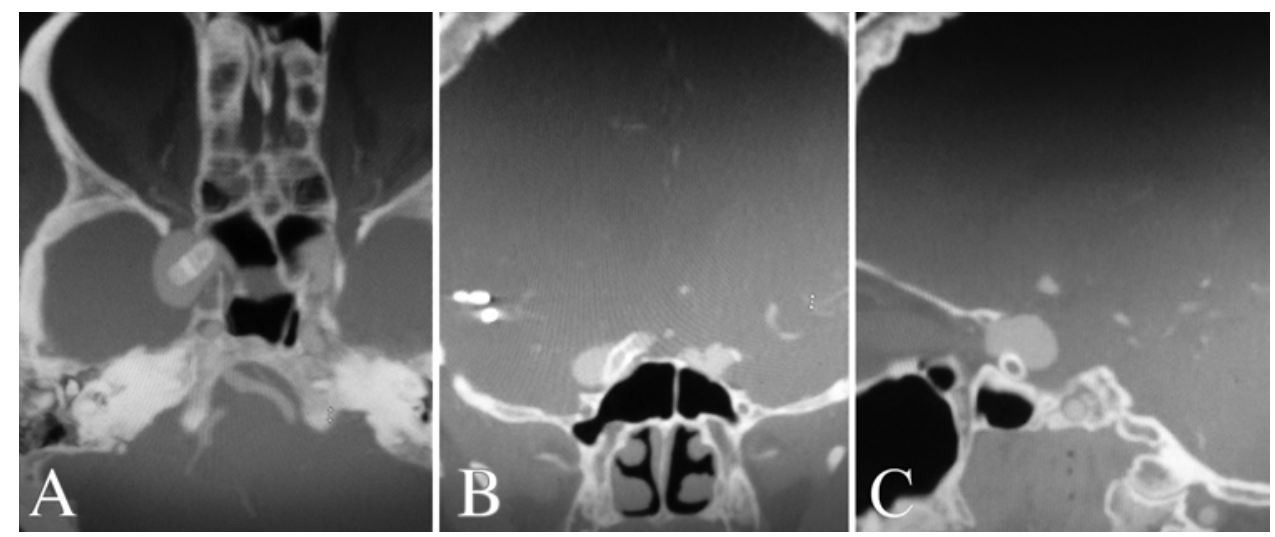

FIG. 3. Axial (A), coronal (B), and sagittal (C) CTA views at 30 months in Case 2. The proximal end of the device remains prolapsed into the aneurysm, with no change in the aneurysm itself.

30-month follow-up, with no change in the aneurysm on follow-up CTA (Fig. 3).

\section{Discussion}

Despite the many strengths of the PED in treating large and giant aneurysms, issues with device sizing, placement, and landing zones remain. ${ }^{24}$ Experienced neurointerventionalists and data support the existence of a learning curve in PED procedures. ${ }^{15}$ The diameters of the inflow and outflow vessels must be accurately determined for appropriate device selection. Oversizing may lead to PED elongation and loss of flow diversion effect. ${ }^{9}$ However, undersizing is perhaps a more grievous error, as it can lead to poor wall apposition and stent migration.

Chalouhi et al. first reported on spontaneous (proximal) migration of a PED in 2013. The device foreshortened by $1 \mathrm{~cm}$ into the aneurysm; the investigators managed to salvage it by accessing the distal ICA and deploying another PED. ${ }^{5}$ The phenomenon has since been described in several case reports ${ }^{26,28}$ and small series. ${ }^{6}$ While most of these PEDs were rescued, there are a few reports describing the potentially fatal consequences. ${ }^{6,28}$ In this paper we describe the first 2 cases in which the foreshortened PED has been left in situ without adverse effect.

In our series, this phenomenon only occurred in widenecked large and giant aneurysms; in our combined experience of more than 400 PED treatments, such foreshortening into the aneurysm did not occur in other cases. While mild foreshortening without prolapse occurred in other cases, this was not reported in our database due to the lack of clinical consequences. In smaller aneurysms, device foreshortening can lead to incomplete aneurysm neck coverage without prolapse, which can be corrected by deploying a second device as distal access is usually maintained in those cases. Wide-necked large and giant aneurysms pose unique challenges to treatment with flow diversion. Due to the size of the lesion, traversing the aneurysm to gain access to the distal vessel can, in itself, be challenging. Next, during deployment, if the forward tension needed to initially advance the catheter is not reduced, the device can take a tortuous pathway through the aneurysm, shortening the length of the proximal landing zone as noted in Case 2.

Also, if forward tension is not applied in adequate amounts to deploy the device in a fully expanded fashion, the stent will be partially stretched within the body of the aneurysm with a natural tendency to foreshorten. Possible delayed or immediate foreshortening would depend on the dynamic interaction of static friction of the stent on the proximal and distal landing zones combating the stored energy of a potentially stretched stent within the body of the aneurysm. Unfortunately, with the PED, relatively lower radial force results in lower levels of static friction in the proximal and distal landing zones compared with a conventional laser-cut self-expanding stent. Even if the stent is deployed with the nominal diameter, eventual overexpansion of the stent within the body of the aneurysm and migration is also possible, given the dynamic energy of blood flow acting on the unopposed, freely hanging portion of the flow diverter within large and giant aneurysms.

Large and giant aneurysms also often require overlapping devices, increasing the risk of prolapse due to device separation. The risk is increased when the overlapping is less than $50 \%$. In cases in which percutaneous transluminal angioplasty (PTA) is necessary to improve device apposition, the device can foreshorten on both ends, leading to prolapse into the aneurysm. These challenges are compounded by increased tortuosity, as seen in the Case 1 .

Some of these challenges could be mitigated by deploying lengthy portions of overlapping PED constructs in the proximal and distal landing zones to combat migration. A high degree of stent overlap can help avoid separation of components from foreshortening. Unfortunately, this solution increases the cost of treatment and potentially increases the thromboembolic complication rate with increased amount of metallic implant and perforator coverage. However, complications are not completely avoidable as giant aneurysms are often not isolated in their pathology, and can arise from multiple dysplastic segments, making device sizing difficult as well. An error in any step during the treatment of large and giant aneurysms can lead to PED migration or foreshortening, leading to prolapse, which can sometimes be rescued by a few techniques.

\section{Causes}

Our study size and incidence rate are insufficient to 
determine the exact associations and causes of PED foreshortening leading to prolapse. However, in conjunction with the experience of others, we have some hypotheses. Illustrative Case 1 occurred in a delayed fashion, whereas Case 2 occurred intraprocedurally.

Case 1 was likely a result of the so-called "watermelon seed effect," wherein a size mismatch between the 2 ends of the stent causes a force to be transmitted from the "squeezed" end to the other, with eventual stent migration. ${ }^{6,11}$ Previously, laser-cut stents were noted to prolapse when deployed in tortuous segments. ${ }^{2,11}$ In this case, a short proximal landing zone $(<5 \mathrm{~mm})$ and vessel tortuosity contributed to the migration and prolapse.

Case 2 involved an acute, intraprocedural prolapse due to a short landing zone, which led to easy, inadvertent foreshortening of the device by the microcatheter during recapture. As described by Kan et al., ${ }^{16}$ another cause was the use of PTA that led to foreshortening of the proximal portion of the distal PED, leading to the construct disconnection in the aneurysm.

Based on our experience of these 3 cases and that of others, it appears that short device length, short landing zone relative to the aneurysm neck, large aneurysm size, multiple devices, and the use of PTA are important risk factors for this phenomenon. However, due to the relative rarity of such cases, it is hard to statistically determine their effect size.

\section{Prevention}

Ideally, the best way to deal with foreshortening is to be vigilant during the procedure and to prevent it. In general, long devices are recommended in larger aneurysms to provide ample proximal and distal coverage. In tenuous cases, one may consider pulling the distal wire into the PED as opposed to re-advancing the microcatheter through the stent, so as not to "bump" and foreshorten the stent. However, care must be taken while pulling the distal wire back into the device so the PED is not foreshortened distally. If access can be maintained, deployment of a second device is an easy remedy. Coils are often used as an adjunct to enhance embolization of giant aneurysms with PED; they may additionally function as a scaffold or to provide support for the PED to prevent migration/foreshortening. ${ }^{22}$ We have also had experience using self-expanding stents to augment the wall apposition and outward radial force of flow diverters at either end in cases of giant aneurysms, which may also prevent migration. ${ }^{20,30}$ As one of the causes discussed is a short landing zone, we recommend generous neck coverage proximally and distally as a way to prevent foreshortening. As the general recommendations are for at least $6 \mathrm{~mm}$ on each side,$^{13}$ we recommend being even more generous and opting for $6-10 \mathrm{~mm}$ of coverage, by use of multiple devices if necessary. To avoid the "watermelon seed effect," we recommend spending time to carefully select the devices necessary, with use of conebeam CT images and luminal reconstruction techniques (including centerline approximation) that can help select device size.

\section{Regaining Distal Access}

The cases described in our series presented a challenge in regaining distal access to the parent vessel. Once the PED has migrated, especially out of the parent artery lumen and into the aneurysm, crossing the PED with a wire is very difficult. We recommend a few rescue techniques that have been successful for such cases. ${ }^{16}$ The key determinant in this challenge is whether the foreshortening occurred on the proximal or distal end of the PED, as the former is far more challenging. When the distal end foreshortens, one can usually still regain distal access. However, when the proximal end prolapses into the aneurysm, the only viable options are transcirculation rescue or technically challenging anterograde reaccess. ${ }^{25}$ The techniques used in previous reports of prolapsed PED are summarized in Table 2.

\section{Retrograde Access}

"Retrograde access" or "transcirculation rescue" 14,29 refers to crossing of the distal device by accessing the vessel

TABLE 2. Published cases of PED prolapse into aneurysms

\begin{tabular}{|c|c|c|c|c|}
\hline Authors \& Year & $\begin{array}{l}\text { Aneurysm } \\
\text { Size }\end{array}$ & Location & $\begin{array}{l}\text { Proximal/Distal End } \\
\text { Foreshortening }\end{array}$ & Remedy \\
\hline Hauck et al., 2010 & $27.5 \times 21 \mathrm{~mm}$ & Lt cavernous ICA & Proximal & Trans-PCoA to deliver 5 overlapping PEDs \\
\hline Chalouhi et al., $2013^{5}$ & $18 \times 13 \mathrm{~mm}$ & Rt cavernous ICA & Distal & Second overlapping PED \\
\hline \multirow[t]{4}{*}{ Chalouhi et al., $2013^{6}$} & $12.7 \times 11.6 \mathrm{~mm}$ & Lt $\mathrm{M}_{1}$ & Proximal & Hemiplegia, occluded $M_{1}$ (no remedy) \\
\hline & $28 \times 23 \mathrm{~mm}$ & Lt supraclinoid ICA & Distal & Coiling of aneurysm \& ICA (parent vessel sacrifice) \\
\hline & "Large" & Rt cavernous ICA & Distal $^{*}$ & Second overlapping PED \\
\hline & $16.5 \mathrm{~mm}$ & Lt cavernous ICA & Distal & Foreshortening proximally, second overlapping PED \\
\hline Navarro et al., 2014 & "Giant" & Rt SCA & Proximal & Patient died prior to revision \\
\hline Bowers et al., 2015 & $3 \times 2.2 \mathrm{~cm}$ & Rt ICA terminus & Distal & Trapping, bypass, \& surgical extraction \\
\hline Crowley et al., 2014 & $2.8 \times 2 \mathrm{~cm}$ & Lt supraclinoid ICA & Distal & Balloon anchoring technique \\
\hline Kan et al., 2015 & $3 \times 2 \mathrm{~cm}$ & Lt cavernous ICA & Proximal & Trans-ACoA to deliver 2 overlapping PEDs \\
\hline Martínez-Galdámez et al., 2017 & $14 \mathrm{~mm}$ & Lt supraclinoid ICA & Proximal & Balloon realignment technique \\
\hline
\end{tabular}

$\mathrm{ACOA}=$ anterior communicating artery; $\mathrm{M}_{1}=\mathrm{M}_{1}$ segment of the middle cerebral artery; $\mathrm{SCA}=$ superior cerebellar artery.

Cases involving rescue for migration alone were omitted.

* Distal end prolapsed into aneurysm, but the proximal end also foreshortened. 
in retrograde fashion, via the anterior or posterior communicating arteries. The wire in the aneurysm is then locked by a snare-loop ${ }^{27}$ so that the microcatheter can regain access to the distal vessel through "flossing." Additional devices can then be deployed.

\section{Sacrifice/Bypass}

Finally, if the device misdeployment cannot be remedied, an option is to sacrifice the involved vessel, with flow restoration via bypass if needed. Excision of the device, though technically possible, should only be attempted in select cases. ${ }^{1,3}$ Microsurgery involving PED-treated vessels, even if not addressing the PED directly, can be quite difficult., ${ }^{4,10,12}$ In Case 1, this was declined by the patient; in Case 2, the patient had already failed a BTO and ipsilateral extracranial-intracranial bypass, so sacrifice was not an option. To have this salvage strategy as an option, it is important to assess collateral circulation and to perform a BTO prior to treatment of these very large and giant aneurysms.

\section{Timing of Rescue}

As either retrograde rescue or anterograde re-access are technically challenging, and given the contrast and fluoroscopy time already spent on the initial procedure, it may be reasonable to attempt the rescue in a separate setting if simple attempts to regain access cannot be accomplished in the same setting. It appears to be safe and preferred given our own experience and the experience reported in the literature (Table 2). However, as a dislodged PED may acutely alter flow dynamics into the aneurysm that could precipitate rupture, ${ }^{28}$ this approach should be considered with caution and based on the unique situation.

\section{Outcomes}

Ultimately, in 2 of the 3 cases in this series, the PED was left in situ. To our knowledge, this is the first report of the outcome of prolapsed PEDs left in situ. One patient was maintained on dual antiplatelet therapy, and the other on $81 \mathrm{mg}$ of aspirin monotherapy. At 1- and 3-year follow-ups, both patients were doing well clinically with no rupture, thrombosis, or thromboembolic events, as well as no change in their aneurysms. However, it is important to note several limitations to these outcomes. The patient in Case 1 was not fully asymptomatic, and suffered diplopia likely related to mass effect or pulsation from the aneurysm, although tolerable. We considered this outcome to be unfavorable but not unreasonable, with a lower threshold for leaving the device in situ in a cavernous aneurysm compared with an intradural aneurysm. While the patients presented in these 2 cases did reasonably well from leaving the device in situ, the outcome is far from ideal. Suffice it to say that it is important to exhaust all rescue options when feasible, as others have reported poor outcomes precipitated by this same phenomenon of aneurysm prolapse (Table 2). 6,28

\section{Conclusions}

The PED is safe and revolutionary in the treatment of large and giant aneurysms, but carries its own unique risks of stent migration or foreshortening that can lead to device prolapse into the aneurysm. With experience, vigilance, and knowledge of rescue techniques, this complication can be deftly avoided or remedied. When a failed construct must be left in situ, it may be surprisingly well tolerated.

\section{References}

1. Abla AA, Zaidi HA, Crowley RW, Britz GW, McDougall CG, Albuquerque FC, et al: Optic chiasm compression from mass effect and thrombus formation following unsuccessful treatment of a giant supraclinoid ICA aneurysm with the Pipeline device: open surgical bailout with STA-MCA bypass and parent vessel occlusion. J Neurosurg Pediatr 14:31-37, 2014

2. Benndorf G, Claus B, Strother CM, Chang L, Klucznik RP: Increased cell opening and prolapse of struts of a neuroform stent in curved vasculature: value of angiographic computed tomography: technical case report. Neurosurgery 58 (4 Suppl 2):ONS-E380, 2006

3. Bowers CA, Taussky P, Park MS, Neil JA, Couldwell WT: Rescue microsurgery with bypass and stent removal following Pipeline treatment of a giant internal carotid artery terminus aneurysm. Acta Neurochir (Wien) 157:2071-2075, 2015

4. Brasiliense LB, Navarro R, Brazis P, Tawk RG: Surgical bailout of giant supraclinoid ICA aneurysm following treatment with Pipeline Embolization Device. J Neurosurg Pediatr 15:338-339, 2015

5. Chalouhi N, Satti SR, Tjoumakaris S, Dumont AS, Gonzalez LF, Rosenwasser R, et al: Delayed migration of a Pipeline Embolization Device. Neurosurgery 72 (2 Suppl Operative):ons229-ons234, 2013

6. Chalouhi N, Tjoumakaris SI, Gonzalez LF, Hasan D, Pema PJ, Gould G, et al: Spontaneous delayed migration/shortening of the Pipeline Embolization Device: report of 5 cases. AJNR Am J Neuroradiol 34:2326-2330, 2013

7. Crowley RW, Abla AA, Ducruet AF, McDougall CG, Albuquerque FC: Novel application of a balloon-anchoring technique for the realignment of a prolapsed Pipeline Embolization Device: a technical report. J Neurointerv Surg 6:439-444, 2014

8. Dashti SR, Fiorella D, Toledo MM, Hu Y, McDougall CG, Albuquerque FC: Proximal migration and compaction of an Enterprise stent into a coiled basilar apex aneurysm: a posterior circulation phenomenon? J Neurointerv Surg 2:356-358, 2010

9. Dholakia R, Sadasivan C, Fiorella DJ, Woo HH, Lieber BB: Hemodynamics of flow diverters. J Biomech Eng 139:021002, 2016

10. Ding D, Starke RM, Liu KC: Microsurgical strategies following failed endovascular treatment with the Pipeline Embolization Device: case of a giant posterior cerebral artery aneurysm. J Cerebrovasc Endovasc Neurosurg 16:26-31, 2014

11. Gao B, Malek AM: Possible mechanisms for delayed migration of the closed cell-designed Enterprise stent when used in the adjunctive treatment of a basilar artery aneurysm. AJNR Am J Neuroradiol 31:E85-E86, 2010

12. Gressot LV, Patel AJ, Srinivasan VM, Arthur A, Kan P, Duckworth EA: An intraoperative look at failure of flow diversion: when additional or alternative treatments should be considered. World Neurosurg 93:486.e7-486.e12, 2016

13. Harrigan MR, Deveikis JP (eds): Handbook of Cerebrovascular Disease and Neurointerventional Technique, ed 2. New York: Springer, 2013

14. Hauck EF, Natarajan SK, Langer DJ, Hopkins LN, Siddiqui AH, Levy EI: Retrograde trans-posterior communicating artery snare-assisted rescue of lost access to a foreshortened Pipeline Embolization Device: complication management. 
Neurosurgery 67 (2 Suppl Operative):495-502, 2010

15. Jabbour P, Chalouhi N, Tjoumakaris S, Gonzalez LF, Dumont AS, Randazzo C, et al: The Pipeline Embolization Device: learning curve and predictors of complications and aneurysm obliteration. Neurosurgery 73:113-120, 2013

16. Kan P, Wakhloo AK, Mokin M, Puri A: Techniques in distal access of wide-necked giant intracranial aneurysms during treatment with flow diversion. Surg Neurol Int 6 (Suppl 7):S284-S288, 2015

17. Kelly ME, Turner RD IV, Moskowitz SI, Gonugunta V, Hussain MS, Fiorella D: Delayed migration of a self-expanding intracranial microstent. AJNR Am J Neuroradiol 29:1959_ 1960, 2008

18. Khatri R, Rodriguez GJ, Siddiq F, Tummala RP: Early migration of a self-expanding intracranial stent after the treatment of a basilar trunk aneurysm: report of a second case. Neurosurgery 69:E513-E517, 2011

19. Kim BM, Shin YS, Baik MW, Lee DH, Jeon P, Baik SK, et al: Pipeline Embolization Device for large/giant or fusiform aneurysms: an initial multi-center experience in Korea. Neurointervention 11:10-17, 2016

20. Kühn AL, Wakhloo AK, Gounis MJ, Kan P, de Macedo Rodrigues K, Lozano JD, et al: Use of self-expanding stents for better intracranial flow diverter wall apposition. Interv Neuroradiol 23:129-136, 2017

21. Lavine SD, Meyers PM, Connolly ES, Solomon RS: Spontaneous delayed proximal migration of Enterprise stent after staged treatment of wide-necked basilar aneurysm: technical case report. Neurosurgery 64:E1012, 2009

22. Lin N, Brouillard AM, Krishna C, Mokin M, Natarajan SK, Sonig A, et al: Use of coils in conjunction with the Pipeline Embolization Device for treatment of intracranial aneurysms Neurosurgery 76:142-149, 2015

23. Lobotesis K, Gholkar A, Jayakrishnan V: Early migration of a self expanding intracranial stent: case report. Neurosurgery 67:E516-E 517, 2010

24. Lubicz B, Collignon L, Raphaeli G, De Witte O: Pipeline flow-diverter stent for endovascular treatment of intracranial aneurysms: preliminary experience in 20 patients with 27 aneurysms. World Neurosurg 76:114-119, 2011

25. Martínez-Galdámez M, Ortega-Quintanilla J, Hermosín A, Crespo-Vallejo E, Ailagas JJ, Pérez S: Novel balloon application for rescue and realignment of a proximal end migrated pipeline flex embolization device into the aneurysmal sac: complication management. J Neurointerv Surg 9:e4-e4, 2017
26. McTaggart RA, Santarelli JG, Marcellus ML, Steinberg GK, Dodd RL, Do HM, et al: Delayed retraction of the Pipeline Embolization Device and corking failure: pitfalls of Pipeline Embolization Device placement in the setting of a ruptured aneurysm. Neurosurgery 72 (2 Suppl Operative):onsE245ons 251,2013

27. Mitchell B, Jou LD, Mawad M: Retrieval of distorted Pipeline Embolic Device using snare-loop. J Vasc Interv Neurol 7:1-4, 2014

28. Navarro R, Cano EJ, Brasiliense LBC, Dabus G, Hanel RA: Fatal outcome after delayed Pipeline Embolization Device migration for the treatment of a giant superior cerebellar artery aneurysm: technical note for complication avoidance. Open J Modern Neurosurg 4:163-168, 2014

29. Navarro R, Yoon J, Dixon T, Miller DA, Hanel RA, Tawk RG: Retrograde trans-anterior communicating artery rescue of unopened Pipeline Embolization Device with balloon dilation: complication management. J Neurointerv Surg 7:e7, 2015

30. Rahal JP, Dandamudi VS, Heller RS, Safain MG, Malek AM: Use of concentric Solitaire stent to anchor Pipeline flow diverter constructs in treatment of shallow cervical carotid dissecting pseudoaneurysms. J Clin Neurosci 21:1024-1028, 2014

\section{Disclosures}

Dr. Puri has served as a consultant to Medtronic, Stryker Neurovascular, and Codman Neurovascular, and has direct stock ownership in InNeuroCo. Dr. Kan is a consultant for Medtronic and Stryker.

\section{Author Contributions}

Conception and design: Kan, Srinivasan. Acquisition of data: Kan, Srinivasan, Carlson, Mokin, Chen, Puri. Analysis and interpretation of data: Kan, Srinivasan, Carlson, Mokin. Drafting the article: Kan, Srinivasan, Carlson. Critically revising the article: all authors. Reviewed submitted version of manuscript: all authors. Study supervision: Kan.

\section{Correspondence}

Peter Kan, Department of Neurosurgery, Baylor College of Medicine, 7200 Cambridge St., Ste. 9A, Houston, TX 77030. email: peter.kan@bcm.edu. 